\title{
MGMT Immunohistochemical Expression in Colorectal Carcinoma and its Correlation with Tumor Progression
}

\author{
Mohamed Ahmed ${ }^{1 *}$, Badawia Bayoumi ${ }^{2}$, Samira Abdallah², Maya Elserafy ${ }^{2}$ \\ ${ }^{1}$ Department of Pathology, Children Cancer Hospital Egypt (57357), Cairo, Egypt; ${ }^{2}$ Department of Pathology, Faculty of \\ Medicine, Cairo University, Giza, Egypt
}

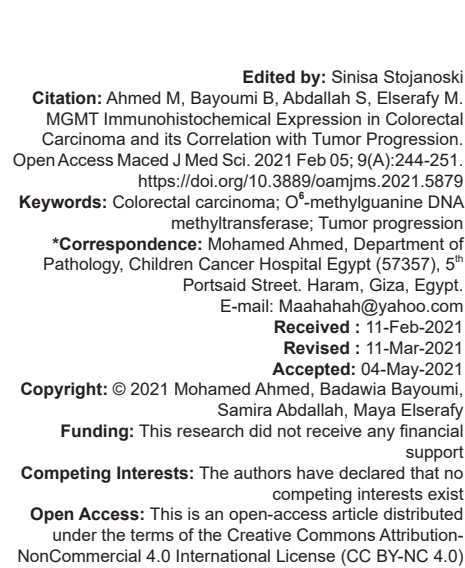

\section{Introduction}

Colorectal cancer (CRC) is the third most commonly diagnosed cancer in males and the second in females worldwide, while according to cancer mortality, $\mathrm{CRC}$ is the third leading cause in both males and females [1]. The development of CRC is complex, with critical role for generation of mutations and failed DNA repair in carcinogenesis. Tumor progression entails the downregulation of damage surveillance mechanisms and necessitates genetic and epigenetic instability to gain uncontrolled proliferation. Epigenetic dysregulation is a driving mechanism in cancer development and progression. This dysregulation is directly acting to modify gene expression through a methylation process of DNA, leading to oncogene activation, tumor suppressor gene silencing, chromosomal instability, and chromatin modification [2], [3], [4].

$0^{6}$-methylguanine DNA methyltransferase (MGMT) is a DNA repair enzyme expressed by all normal human cells, it prevents DNA mutations and damage due to alkylating agents, then undergoes self-inactivation.
Expression of MGMT gene varies in normal and neoplastic tissues. Furthermore, MGMT epigenetic silencing is linked to its lack of expression through the methylation process. Loss of MGMT expression has a significant role in carcinogenesis in various tumors as gliomas, non-small cell lung carcinoma, and diffuse large B-cell lymphoma [5], [6], [7]. Temozolomide (TMZ), an alkylating chemotherapeutic drug, is widely used to treat glioblastoma patients. It triggers death of tumor cells by alkylating DNA. However, some tumor cells are able to repair this type of DNA damage and diminish its therapeutic efficacy. The most important DNA repair system impacting the mechanism of action and cytotoxicity of TMZ is the MGMT. Therefore, loss of expression or depletion of MGMT is highly correlated with cytotoxic sensitivity to $\mathrm{TMZ}$, which is widely used for the treatment of glioblastoma [8], [9], [10], [11].

Many histopathologic parameters in many types of cancers and mainly CRC gained attention in the last decade, for their impact on prognosis and survival as they reflect biologic behavior of the cancer, however, are not always included in the diagnostic pathology reports; desmoplastic reaction (DR), tumor budding, 
tumor infiltrating lymphocytes (TIL), and Crohn's-like lymphoid reaction (CLR), tumor invasive front pattern and necrosis are from those main parameters [12], [13], [14], [15], [16], [17], [18], [19].

The aim of this study is to evaluate the expression of MGMT in CRC and to correlate this expression with different clinicopathological aspects as well as to evaluate the relationship between different histopathologic parameters in CRC with tumor progression.

\section{Materials and Methods}

\section{Collection of specimens}

The study was carried on a total of 70 colectomy specimens of patients with colorectal cancer not subjected to chemo-radiotherapy nor with missing data, tumor sections were formalin fixed and paraffin embedded. Specimens were sampled by simple random method from the Department of Pathology of Kasr El-Aini Hospital, Faculty of Medicine, Cairo University during the period between (March - 2017 and May - 2018). The study was approved by the ethical committee of Kasr El-Aini Hospital and specimens were anonymously replaced by numbers for confidentiality.

The site of the tumor was classified into colonic and rectum, while the size of the tumor was calculated as the length of the largest diameter. The tumor extension into other organs, distant metastasis if present and the lymph node status were also obtained from the diagnosis present in the pathology reports (clinical data of distant metastasis in other organs detected at time of diagnosis were also obtained from the patient's sheet). Mucinous and signet ring cases were excluded from grading.

\section{Processing and histopathologic examination}

Paraffin blocks of the tumor were serially sectioned at $4 \mu \mathrm{m}$ thickness. Afterward, they were stained with routine hematoxylin-eosin stain for evaluation and confirmation of the diagnosis, assessment of histologic type and grade, detection of the tumor invasion depth, lymph node status and the presence of lympho-vascular and perineural invasion, according to the recommendations of the World Health Organization, while staging was performed using TNM 8th edition system for each case [12], [13]. Histopathologic examination was performed by one pathologist (MA). All microscopic measurements were taken using Leica slide scanner SCN400 and image viewer software (Leica Microsystems).

Tumor invasive front pattern was assessed whether infiltrative with jagged border or pushing with relative smooth border. Tumor budding was assessed according to the International Tumor Budding Consensus Conference, as isolated cancer cells or a cluster of $<5$ neoplastic cells at the invasive front of the tumor. The invasive front of the tumor was assessed at a scanning (x10 objective) magnification for the area with maximal tumor budding. In this area, the number of tumor buds was determined in a $0.785 \mathrm{~mm}^{2}$ area. Tumors were classified as absent budding, low tumor budding if 1-9 tumor buds, and high tumor budding if $\geq 10$ tumor buds were identified per $0.785 \mathrm{~mm}^{2}$ area [14].

DR was histologically assessed in the reactive fibrous zone at the advancing extramural edge of the tumor and classified into three categories: Mature when fibrotic stroma did not contain keloid-like collagen or myxoid stroma and was composed of fine mature collagen fibers stratified into multiple layers. Intermediate when keloid-like collagen observed as hyalinized thick bundles of hypocellular collagen was intermingled with mature stroma. Immature when stroma show myxoid changes comprising slightly basophilic extracellular matrix. The stroma is classified according to the most immature stromal area. A microscopic field of a $\times 40$ objective was used as a cutoff [15]. DR was not assessed in 14 cases which represented T1 and T2 cases which by definition have not an extramural invasive component.

Inflammatory lymphocytic milieu was histologically assessed as TIL with categorization into two groups: Intraepithelial (TIL-E) assessed in 5 HPF, in the invasive front and center of tumor and classified as absent, one per gland (cancer Tube) or more per gland, excluding necrotic, and apoptotic areas.[16] Stromal (TIL-S) assessed in the center and invasive front of the tumor in a percentage of stromal inflammatory cells and scored in 5\% increments excluding necrotic and fibrotic areas, immune infiltrate outside of the tumor and granulocytic infiltrate areas, according to International TILs Working Group into three categories: Low $(0-10 \%)$, moderate (15-50\%), and high (>50\%) of stroma [17]. CLR density is measured as number of lymphoid aggregates per $\mathrm{mm}$ length of tumor front and was scores as absent, low or high CLR density using cutoff ( $>0.38$ follicles $/ \mathrm{mm}$ ) of length [18].

Tumor necrosis was assessed in the tumor's center excluding luminal necrotic debris and graded as "absent" (0), "focal" (<10\%), "moderate" (10-30\%) or "extensive" (>30\%) of tumor area [19].

\section{Immunohistochemistry (IHC)}

Another unstained paraffin section on positive charged slides from each case was loaded in IHC autostainer (Ventana Benchmark XT. Roche Diagnostics) and processed for immunostaining with Mouse monoclonal MGMT antibody (Santa Cruz Biotechnology) with a dilution 1:50, using Optiview IHC detection kit. MGMT external positive control of a lymph 
node was used as well as internal control of lymphocytes, plasma cells, stroma, and blood vessels. Lymph node tissue was also assayed omitting the primary antibody as negative controls. Immunohistochemical staining of MGMT was evaluated as positive only with nuclear staining in tumor cells, while cytoplasmic staining is disregarded. A semi-quantitative scoring system for both staining intensity and the percentage of positive cells was used. A score was calculated by multiplying the intensity (negative: 0 , mild: 1 , moderate: 2 , and strong: 3 ) by percentage of stained cells (0: absent, 1 : $1-25 \%, 2$ : $>25-50 \%, 3:>50-75 \%$, and $4:>75-100 \%)$. Scores of multiplication were graded as follows: $(-): 0$, $(+)$ : 1-3, (++): 4-8, and (+++): 9-12. In addition, for statistical analysis, the $(-)$ and $(+)$ cases were pooled into the low-expression group, and the $(++$ and +++$)$ cases were pooled into the high-expression group [20]. Immunostaining of additional tumor section was applied to cases with variation in the intensity of staining in multiple fields in the same tumor section. IHC interpretation and score assessment were performed by two pathologists (MA and MS). MGMT expression was studied with the different previously mentioned clinicopathologic aspects of CRC in collected cases.

\section{Statistical methods}

Data were statistically described in terms of mean \pm standard deviation $( \pm S D$ ), median and range, or frequencies (number of cases) and percentages when appropriate. Percentages were approximated taking in consideration total percentage to be $100 \%$. Comparison of numerical variables between the study groups was done using Mann Whitney $U$ test for independent samples to compare 2 groups. For comparing categorical data, Chi square $\left(x^{2}\right)$ test was performed. Exact test was used instead when the expected frequency is $<5$. $p<0.05$ was considered statistically significant flagged with an asterisk, $<0.01$; highly significant flagged with 2 asterisks and $<0.001$ is extremely significant flagged with 3 asterisks. ShapiroWilk test was included for normality. All statistical calculations were done using Statistical Package for the Social Science (SPSS version 20.).

\section{Results}

The study included 70 cases of CRC with age ranging between 11 and 82 years old, mean age was 51.4 years and median age was 55 years. Three patients (4.3\% of cases) were younger than 18 years. Males constituted $57.1 \%$ and females $42.9 \%$ of cases. Low MGMT expression was detected in $42.9 \%$ of all cases. Mean and median age for low MGMT expression group were 51.1 and 55 years, respectively, while those of high MGMT expression group were 51.6 and 52.5 years, respectively. Mean size of the tumor was $5.7 \mathrm{~cm}$ (ranging between 2.5 and $11 \mathrm{~cm}$ ) with low MGMT expression detected in $46.7 \%$ of size $\geq 5 \mathrm{~cm}$ and $36 \%$ of size $<5 \mathrm{~cm}$, with no statistically significant difference $(p>0.05)$. Figure 1 displays low and high expression of MGMT. Age, tumor size, and MGMT expression show normal distribution according to Shapiro-Wilk normality test $(p<0.05)$, except for tumor size in the high MGMT expression group $(p=0.013)$.

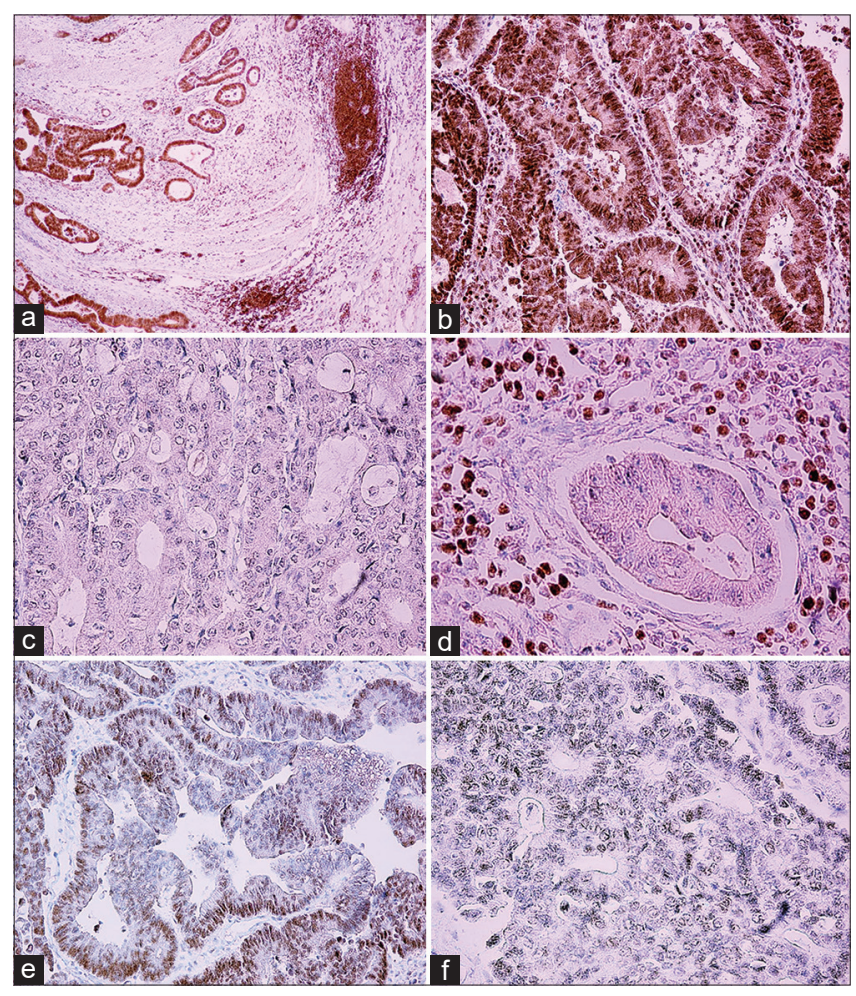

Figure 1: Immunohistochemical stained sections illustrate O6-methylguanine DNA methyltransferase (MGMT) expression; (a and b) low and high magnification showing; positive nuclear reaction score 12 (High expression). (c and d) Low and high magnification showing negative reaction to MGMT score 0 (Low expression). (e) Positive nuclear reaction intensity 2 and percentage 3; Score 6 (High expression). (f) Positive weak nuclear reaction intensity 1 and percentage 3, Score 3 (Low expression). (a, b, and c) Positive internal control lymphocytes

Regarding tumor stage and MGMT expression, low expression was detected in $54.4 \%$ of Stage I, $25 \%$ of Stage II, $60 \%$ of Stage III, and $11.1 \%$ of Stage IV, with a statistically significant relationship $(p=0.0146)$.

Table 1 summarizes the relationship between tumor staging with MGMT and some clinico-pathologic parameters. Despite there was not a statistically significant relationship ( $p>0.05$ ) between MGMT expression and primary tumor extension, a direct linear correlation between increase in MGMT expression and higher primary tumor extension $(\mathrm{T})$ stage was noted. There were no statistically significant relationship ( $p>0.05$ ) between MGMT expression with age, sex, tumor size, site, lymph node status, tumor differentiation, histologic type, lymphovascular and perineural invasion, tumor budding, pattern of invasive front, TIL, CLR, DR, 
Table 1: The relationship between MGMT and clinicopathologic parameters with tumor staging

\begin{tabular}{|c|c|c|c|c|c|c|}
\hline Parameter & No (\%) & Stage I & Stage II & Stage III & Stage IV & $p$-value \\
\hline \multicolumn{7}{|l|}{ MGMT } \\
\hline High expression & $40(57.1)$ & $5(45.6)$ & $15(75)$ & $12(40)$ & $8(88.9)$ & \multirow[t]{2}{*}{$0.0146^{*}$} \\
\hline Low expression & 30 (42.9). & $6(54.4)$ & $5(25)$ & $18(60)$ & $1(11.1)$ & \\
\hline \multicolumn{7}{|l|}{ Stroma } \\
\hline Mature & $19(33.9)$ & NA & $11(55)$ & $7(25.9)$ & $1(11.1)$ & \multirow[t]{3}{*}{$0.0353^{*}$} \\
\hline Intermediate & $23(41.1)$ & NA & $7(35)$ & $13(48.2)$ & $3(33.3)$ & \\
\hline Immature & $14(25)$ & NA & $2(10)$ & $7(25.9)$ & $5(55.6)$ & \\
\hline \multicolumn{7}{|l|}{ Budding } \\
\hline Absent & $20(28.6)$ & $7(63.6)$ & $8(40)$ & $4(13.3)$ & $1(11.1)$ & \multirow[t]{3}{*}{$0.0185^{*}$} \\
\hline Low & $23(32.8)$ & $3(27.3)$ & $6(30)$ & $12(40)$ & $2(22.2)$ & \\
\hline High & $27(38.6)$ & $1(9.1)$ & $6(30)$ & $14(46.7)$ & $6(66.7)$ & \\
\hline \multicolumn{7}{|l|}{ Invasive front } \\
\hline Pushing & $7(10)$ & $3(27.3)$ & $1(5)$ & $3(10)$ & $0(0)$ & \multirow[t]{2}{*}{0.157} \\
\hline Infiltrative & $63(90)$ & $8(72.7)$ & $19(95)$ & $27(90)$ & $9(100)$ & \\
\hline \multicolumn{7}{|c|}{ Tumor infiltrating lymphocytes stromal } \\
\hline Low & $38(54.3)$ & $4(36.4)$ & $17(85)$ & $13(43.3)$ & $4(44.45)$ & \multirow[t]{3}{*}{$0.0188^{*}$} \\
\hline Intermediate & $26(37.1)$ & $5(45.4)$ & $1(5)$ & $16(53.3)$ & $4(44.45)$ & \\
\hline High & $6(8.6)$ & $2(18.2)$ & $2(10)$ & $1(3.4)$ & $1(11.1)$ & \\
\hline \multicolumn{7}{|c|}{ Tumor infiltrating lymphocytes intraepithelial } \\
\hline Absent & $18(25.7 \%)$ & $0(0 \%)$ & $5(25 \%)$ & $10(33.3 \%)$ & $3(33.3 \%)$ & \multirow[t]{3}{*}{0.161} \\
\hline 1 & $44(62.9 \%)$ & $8(72.7 \%)$ & $14(70 \%)$ & $18(60 \%)$ & $4(44.5 \%)$ & \\
\hline$>1$ & $8(11.4 \%)$ & $3(27.3 \%)$ & $1(5 \%)$ & $2(6.7 \%)$ & $2(22.2 \%)$ & \\
\hline \multicolumn{7}{|c|}{ Crohn's-like lymphoid reaction } \\
\hline Absent & $33(47.2 \%)$ & $7(63.6 \%)$ & $10(50 \%)$ & $11(36.7 \%)$ & $5(55.6 \%)$ & \multirow[t]{3}{*}{0.780} \\
\hline Low & $25(35.7 \%)$ & $3(27.3 \%)$ & $7(35 \%)$ & $12(40 \%)$ & $3(33.3 \%)$ & \\
\hline High & $12(17.1 \%)$ & $1(9.1 \%)$ & $3(15 \%)$ & $7(23.3 \%)$ & $1(11.1 \%)$ & \\
\hline \multicolumn{7}{|l|}{ Necrosis } \\
\hline Absent & $17(24.3 \%)$ & $8(72.7 \%)$ & $1(5 \%)$ & $6(20 \%)$ & $2(22.2 \%)$ & \multirow[t]{4}{*}{$0.0032^{* *}$} \\
\hline Focal & $35(50 \%)$ & $2(18.2 \%)$ & $12(60 \%)$ & $15(50 \%)$ & $6(66.7 \%)$ & \\
\hline Moderate & $16(22.8 \%)$ & $1(9.1 \%)$ & $6(30 \%)$ & $9(30 \%)$ & $0(0 \%)$ & \\
\hline Extensive & $2(2.9 \%)$ & $0(0 \%)$ & $1(5 \%)$ & $0(0 \%)$ & $1(11.1 \%)$ & \\
\hline
\end{tabular}

or necrosis. Table 2 shows the frequencies of clinicopathologic parameters and the relationship with MGMT expression. Figure 2 demonstrates microscopically many histopathologic features.

DR, tumor budding, TIL-S, and Necrosis were statistically correlated with the tumor stage $(p=0.035$, $0.018,0.018$, and 0.0032 , respectively). DR immaturity showed a statistically significant directly proportional relationship with tumor budding $(p=0.0014)$ (Figure 3$)$. Interestingly, both types of TILand CLR show a statistically significant relationship; TIL-S with TIL-E, TIL-E with CLR as well TIL-S with CLR $(p<0.001, p=0.0024$, and $p<0.001$, respectively) (Table 3 ).

\section{Discussion}

MGMT low expression group represented $42.9 \%$ of cases, higher than Michailidi's and Pietrantonio's studies; $34 \%$ and $37 \%$, respectively, while lower than Oliver's study 48.2\% [21], [22], [23]. MGMT low expression group was more frequent in females $50 \%$ than in males $37.5 \%$, similar to Zhang's and Michailidi's studies, and in contrast to Oliver's study that demonstrated MGMT low expression group was more predominant in males than in females. Regarding the age, Michailidi's study showed higher mean age for both low and high MGMT expression categories 69.5 and 66.9 years, respectively, while for median age Zhang's study showed slightly higher median for both MGMT low and high expression categories 57 and 58 years, respectively. Concerning tumor site, our study showed MGMT low expression group in the colonic and rectal
Table 2: The relationship between MGMT expression and clinico-pathologic factors

\begin{tabular}{|c|c|c|c|c|}
\hline Factors & No. $(\%)$ & High expression & Low expression & $\mathrm{p}$-value \\
\hline \multicolumn{5}{|l|}{ Sex } \\
\hline Male & $40(57.1)$ & $25(62.5)$ & $15(37.5)$ & \multirow[t]{2}{*}{0.422} \\
\hline Female & $30(42.9)$ & $15(50)$ & $15(50)$ & \\
\hline \multicolumn{5}{|l|}{ Age } \\
\hline$<60$ & $41(58.6)$ & $21(51.2)$ & $20(48.8)$ & \multirow[t]{2}{*}{0.233} \\
\hline$\geq 60$ & $29(41.4)$ & 19 (65.5) & $10(34.5)$ & \\
\hline \multicolumn{5}{|l|}{ Size } \\
\hline$\geq 5 \mathrm{~cm}$ & $45(64.3)$ & $24(53.3)$ & $21(46.7)$ & \multirow[t]{2}{*}{0.387} \\
\hline$<5 \mathrm{~cm}$ & $25(35.7)$ & $16(64)$ & $9(36)$ & \\
\hline \multicolumn{5}{|l|}{ Primary tumor site } \\
\hline Colonic & $51(72.9)$ & $31(60.8)$ & $20(39.2)$ & \multirow{2}{*}{0.312} \\
\hline Rectal & $19(27.1)$ & $9(47.4)$ & $10(52.6)$ & \\
\hline \multicolumn{5}{|c|}{ Primary tumor extension } \\
\hline $\mathrm{T} 1$ & $2(2.9)$ & $0(0)$ & $2(100)$ & \multirow[t]{4}{*}{0.389} \\
\hline T2 & $12(17.1)$ & $6(50)$ & $6(50)$ & \\
\hline T3 & $46(65.6)$ & $27(58.7)$ & $19(41.3)$ & \\
\hline T4 & $10(14.3)$ & $7(70)$ & $3(30)$ & \\
\hline \multicolumn{5}{|l|}{ Lymph node status } \\
\hline No & $31(44.3)$ & $18(58.1)$ & $13(41.9)$ & \multirow{3}{*}{0.889} \\
\hline $\mathrm{N} 1$ & $26(37.1)$ & $14(53.8)$ & $12(46.2)$ & \\
\hline N2 & 13 (18.6) & $8(61.5)$ & $5(38.5)$ & \\
\hline \multicolumn{5}{|l|}{ Distant metastasis } \\
\hline M0 & $61(87.1)$ & $32(52.5)$ & $29(47.5)$ & $0.0392^{*}$ \\
\hline M1 & $9(12.9)$ & $8(88.9)$ & $1(11.1)$ & \\
\hline Histologic type & & & & \\
\hline Adenocarcinoma & $67(95.7)$ & $39(58.2)$ & $28(41.8)$ & 0.666 \\
\hline Mucinous & $2(2.9)$ & 1 (33.33) & 1 (33.33) & \\
\hline Signet ring & $1(1.4)$ & & & \\
\hline Differentiation & & & & \\
\hline GI & $2(3)$ & $1(50)$ & $1(50)$ & 0.834 \\
\hline G II & $59(88)$ & $32(54.2)$ & $27(45.8)$ & \\
\hline G III & $6(9)$ & $4(66.7)$ & $2(33.3)$ & \\
\hline Lymphovascular inv & & & & \\
\hline Detected & 38 (54.3). & $22(57.9)$ & $16(42.1)$ & 0.889 \\
\hline Not detected & $32(55.7)$ & $18(56.2)$ & $14(43.8)$ & \\
\hline Perineural invasion & & & & \\
\hline Detected & $16(22.9)$ & $6(37.5)$ & $10(62.5)$ & 0.771 \\
\hline Not detected & $54(77.1)$ & $34(63)$ & $20(37)$ & \\
\hline Tumor budding & & & & \\
\hline Absent & $20(28.6)$ & $14(70)$ & $6(30)$ & 0.325 \\
\hline Low & $23(32.8)$ & $13(56.5)$ & $10(43.5)$ & \\
\hline High & 27 (38.6) & $13(48.1)$ & $14(51.9)$ & \\
\hline Tumor invasive fron & & & & \\
\hline Pushing & $7(10)$ & $3(42.9)$ & $4(57.1)$ & 0.687 \\
\hline Infiltrating & $63(90)$ & $37(58.7)$ & $26(41.3)$ & \\
\hline Crohn like reaction & & & & \\
\hline Absent & $33(47.2)$ & $22(66.7)$ & $11(33.3)$ & 0.263 \\
\hline Low & 25 (35.7) & $13(52)$ & $12(48)$ & \\
\hline High & $12(17.1)$ & $5(41.7)$ & $7(58.3)$ & \\
\hline Desmoplastic reacti & & & & \\
\hline Mature & 19 (33.9) & $12(63.2)$ & $7(36.8)$ & 0.864 \\
\hline Intermediate & $23(41.1)$ & $13(56.5)$ & $10(43.5)$ & \\
\hline Immature & $14(25)$ & $9(64.3)$ & $5(35.7)$ & \\
\hline TIL-E & & & & \\
\hline Absent & $18(25.7)$ & $9(50)$ & $9(50)$ & 0.649 \\
\hline 1 & $44(62.9)$ & $27(61.4)$ & $17(38.6)$ & \\
\hline$>1$ & $8(11.4)$ & $4(50)$ & $4(50)$ & \\
\hline TIL-S & & & & \\
\hline $0-10 \%$ & $38(54.3)$ & $22(57.9)$ & $16(42.1)$ & 0.840 \\
\hline $15-50 \%$ & $26(37.1)$ & $14(53.8)$ & $12(46.2)$ & \\
\hline$>50 \%$ & $6(8.6)$ & $4(66.7)$ & $2(33.3)$ & \\
\hline Necrosis & & & & \\
\hline Absent & $17(24.3)$ & $8(47.1)$ & $9(52.9)$ & 0.285 \\
\hline Focal & $35(50)$ & $24(68.6)$ & $11(31.4)$ & \\
\hline Moderate & $16(22.8)$ & $7(43.7)$ & $9(56.3)$ & \\
\hline Extensive & $2(2.9)$ & $1(50)$ & $1(50)$ & \\
\hline
\end{tabular}

cases representing $39.2 \%$ and $52.6 \%$, respectively, higher than what Zhang et al. found; $26.7 \%$ in colonic cases and $32.3 \%$ in rectal cases [24]. The differences between age, gender, and tumor site at one side in relation with MGMT expression at the other side could be attributed to differences in the racial and environmental factors between populations as all the patients included in the current study are Egyptians. Tumor histologic type and differentiation lack statistical significance with MGMT expression, while Zhang et al. found a statistical correlation between histologic type and low MGMT expression which was more common in signet ring cell carcinoma $80 \%$, but they couldnot detect a signficant 


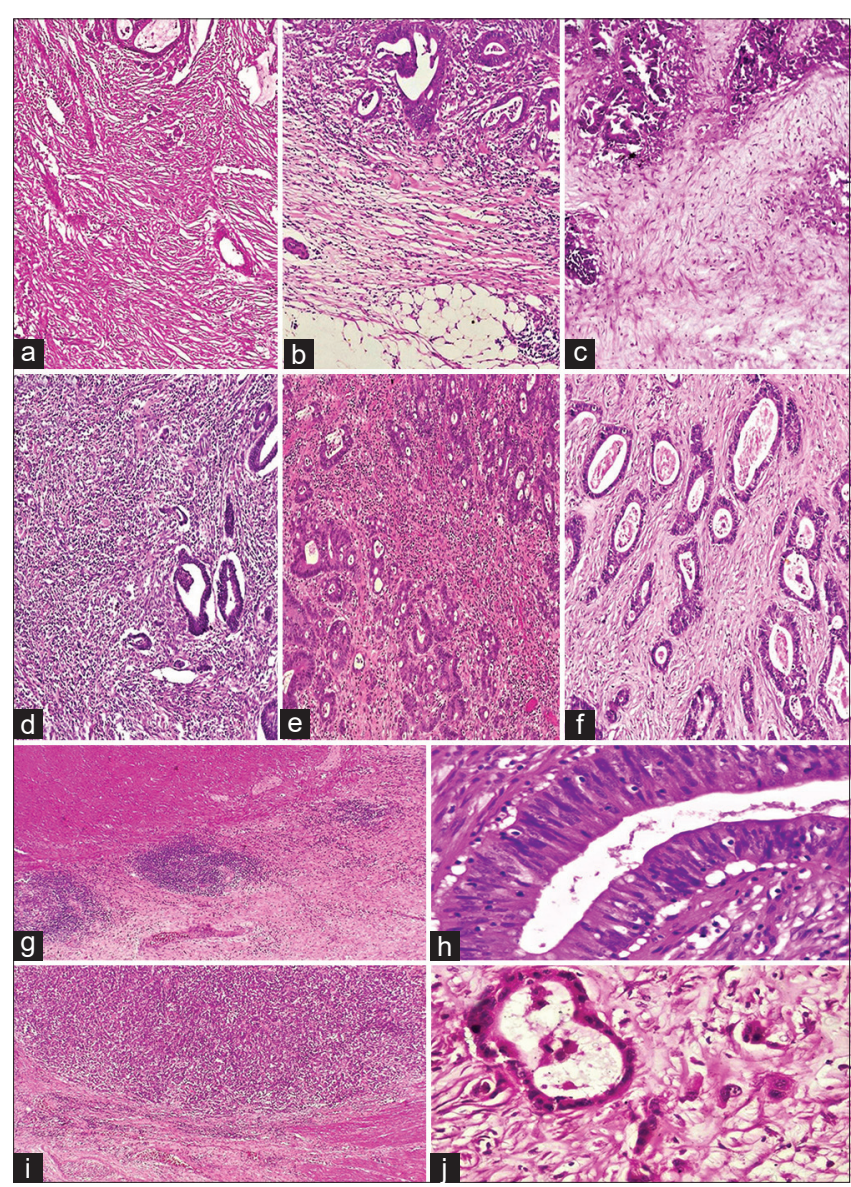

Figure 2: H\&E stained sections illustrate Desmoplastic reaction (a $b$, and $c$, mature; intermediate and immature respectively). Tumor infiltrating lymphocytes stromal (d, e, and $f ;>50 \%, 15-50 \%$, and $<10 \%$, respectively). (g) Crohn's-like lymphoid reaction density ( $>0.38$ follicles $/ \mathrm{mm}$ ). (h) tumor infiltrating lymphocytes intraepithelial $>1 /$ tube. (i) Pushing invasive front. (j) Tumor budding. clusters of $<5$ cells. (Field diameter $4.9 \mathrm{~mm}$. original magnification $\times 40$ for $\mathrm{G}$ and I)

correlation with the tumor grade in the same study. Liddell et al. found frequent loss of MGMT expression in mucinous adenocarcinoma 23\% [24], [25].

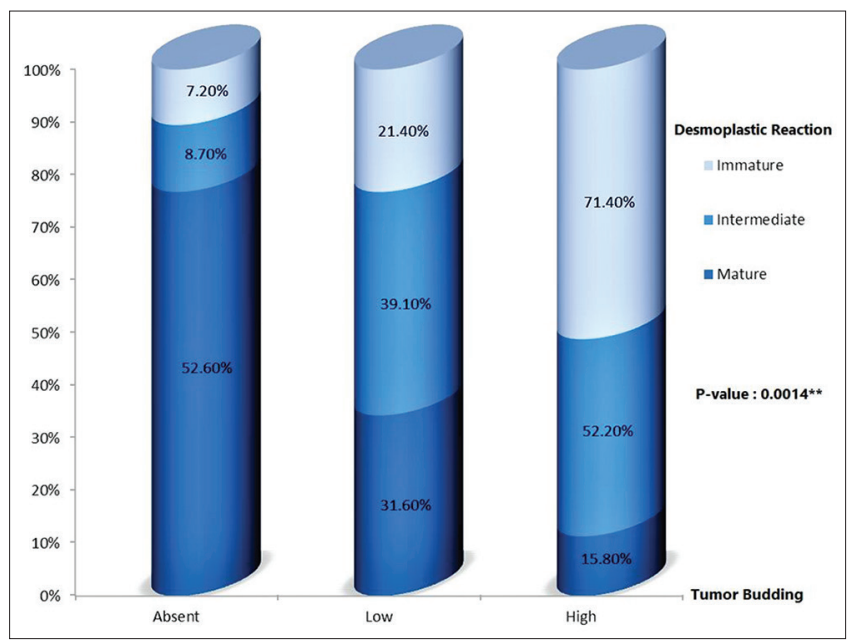

Figure 3: Histogram showing the significant relationship between desmoplastic reaction and tumor budding; the immaturity of stroma is directly proportional to the increase in budding

On basis of DR categorization and tumor budding, both lacked significant correlation with MGMT expression, however both showed a statistically significant correlation with TNM stage group. In addition, DR and tumor budding correlated significantly with each other, representing as possible surrogate markers for epithelial mesenchymal transition [26], [27]. Our results are in agreement with data reported by Ueno, as regard distribution of DR categories, and the significant correlation between DR with TNM status and tumor budding [14]. This could confirm the conclusion that the more immaturity of the stroma the more tumor progression and the risk of metastasis. Tumor budding in CRC and other tumors, is known to be an independent prognostic factor for metastatic potential and cancer related death [28]. Our results indicate that tumor budding and immaturity of stroma go hand in hand. The pattern of invasive front did not correlate with MGMT expression nor TNM stage grouping and could need to be correlated with microsatellite instability (MSI) which was not done in this study.

Regarding the inflammatory lymphocytic milieu of tumor, neither TIL-S, TIL-E, nor CLR correlated significantly with MGMT expression. An interesting significant relationship was noted between any two elements of the studied lymphocytic triad, that is, TIL-S with TIL-E, TIL-S with CLR, and TIL-E with CLR, similar to what Jakubowska found at the invasive front of the tumor [15]. This could support that the inflammatory lymphocytic milieu are orchestrated or directed along the same course of tumor's immune status, as evidenced by immunohistochemical studies that demonstrated mixed B- and T-cell elements in CLR and variable T- cell subsets in TIL [17]. The current study also showed that only TIL-S showed a correlation with the TNM stage grouping. Most other studies correlated high density TIL and CLR with TNM stage grouping, favorable prognosis and overall survival, with additional significant correlation between TIL-E and CLR as well as TIL-E and TIL-S. [17], [29], [30], [31]. Necrosis did not correlate significantly with MGMT expression, yet it was significantly correlated with TNM stage grouping, which was also reported by Pollheimer. This could be due to rapid tumor growth and reflecting hypoxic changes, and in turn, correlate with increase in metastatic potential and adverse prognosis [32]. To the best of our knowledge, no data were published in the literature about the relation between DR, tumor budding, invasive front pattern, inflammatory lymphocytic milieu, and necrosis with MGMT expression status.

In this study, tumor invasiveness $(T)$ was directly correlated with increase in MGMT expression where none of T1 cases showed high expression while T4 showed the highest expression in $70 \%$ with insignificant correlation $(p=0.889)$ which may raise a possibility that tumors with intact MGMT expression have more capability of growth and local invasion, although this needs more number of cases to be studied to confirm this current suggestion. Besides detection of MGMT low expression in T1 and T2 could give a clue that loss of MGMT is not a late event in CRC 
Table 3: Inflammatory lymphocytic milieu; TIL-S, TIL-E, and CLR relationship

\begin{tabular}{|c|c|c|c|c|c|c|c|c|}
\hline \multirow{2}{*}{$\begin{array}{l}\text { Parameters } \\
\text { TIL-S }\end{array}$} & \multicolumn{3}{|c|}{ TIL-E No. (\%) } & \multirow[t]{2}{*}{$p$-value } & \multicolumn{3}{|c|}{ CLR No. (\%) } & \multirow[t]{2}{*}{$p$-value } \\
\hline & Absent & 1 & $>1$ & & Absent & Low & High & \\
\hline Low & $16(42.1)$ & $22(57.9)$ & 0 & $<0.001^{* \star *}$ & $12(41.4)$ & $16(55.2)$ & $1(3.4)$ & $<0.001^{\star \star \star}$ \\
\hline Moderate & $2(7.7)$ & 20 (76.9) & $4(15.4)$ & & $21(60)$ & $7(20)$ & $7(20)$ & \\
\hline High & 0 & $2(33.3)$ & $4(66.7)$ & & 0 & $2(33.3)$ & $4(66.7)$ & \\
\hline \multicolumn{9}{|l|}{ CLR } \\
\hline Absent & $6(18.2)$ & $24(72.7)$ & $3(9.1)$ & $0.0024^{\star \star}$ & & & & \\
\hline Low & $12(48)$ & $12(48)$ & $1(4)$ & & & & & \\
\hline High & 0 & $8(66.7)$ & $4(33.3)$ & & & & & \\
\hline
\end{tabular}

invasive phase and is related to invasive properties not the tumor size of the non-invasive growth, as it is noticed also from the percentage of low expression in tumors $<5 \mathrm{~cm}$ previously mentioned. According to lymph node status (N), low MGMT expression was detected in $43.6 \%$ of $\mathrm{N} 1$ and $\mathrm{N} 2$ cases. This result is within the range between Zhang's and Michailidi's studies, both without significant statistical correlation [21] [24].

According to the presence or absence of metastasis (M) and TNM stage grouping, low expression of MGMT was detected in one of the nine metastatic cases, a significant correlation between MGMT high expression and stage grouping was detected $(p=0.0146)$. Studies done by Zhang, SartoreBianchi and Morano reported higher percentage of their cases with MGMT low expression in metastatic cases $24.2 \%, 43 \%$, and $72 \%$, respectively, with their studies focusing on Stage IV disease, while Michailidi found loss of MGMT expression in $50 \%$ of metastatic cases in a study involving the four stages using Duke's staging system with significant statistical correlation [19]. The discrepancy in percentages is attributed to the type of study whether random or non-random, the number of cases and the scoring system used in assessment of MGMT IHC. Even though our study showed low MGMT expression in a low percentage of the metastatic cases, which theoretically could be disappointing, this will not preclude any benefit gained from applying MGMT detection in metastatic CRC cases and the trials using alkylating chemotherapeutics, as TMZ for cases with low expression [33]. Furthermore, Mori showed that patients with methylation and loss of expression of MGMT in tissue are valuable biomarkers for detection of Stage III CRC at high risk of recurrence [34]. It is worth mentioning that our study included four cases (colonic and Stage II) that showed low MGMT expression, one of them showed perineural invasion, and one of the high-risk features. Interestingly, a clinical trial using a combination of $\mathrm{TMZ}$ and Irinotecan for pretreated metastatic CRC, showed that all non-responder patients were MGMT positive by IHC, while patients with MGMT negative or low had a significantly longer median progression free-survival than others [33]. In addition. Shah et al. observed concordance between MGMT gene promoter methylation status and MGMT $\mathrm{IHC}$ results in Glioblastoma using the same IHC clone [35], making MGMT worth for investigation.

\section{Limitations and recommendation of the} study

This study has several potential limitations; first, the lack of detection of MGMT by methylation assay combined with IHC which could be more confirmative to the role MGMT in the pathogenesis of colorectal carcinoma, second, the lack of MSI status as we predict that it will show correlation with MGMT expression and many of the studied histopathological parameters and so additional molecular correlation is needed especially with known prognostic genes as KRAS and BRAF. Third, the lack of 5 year survival, as to date, the cases were collected from only $<3$ years ago and this period will not be enough to use prognostically; therefore, further studies with larger samples for pretreated cases and long-term follow-up are required to establish prognostic significance of MGMT and the other histopathologic parameters. In addition, Loss of MGMT might be of interest in metastatic and recurrent $\mathrm{CRC}$ to select cases that could benefit from alkylating chemotherapeutics, as TMZ. Finally, further studies focusing on the biology of tumor microenvironment are needed to characterize its role in carcinogenesis.

\section{Conclusion}

MGMT high expression showed a statistically significant correlation with tumor stage grouping and can be correlated with CRC progression. MGMT Low expression was detected in $42.9 \%$ of CRC cases and in $11.1 \%$ of metastatic cases, which might be a valuable biomarker in selection of metastatic and recurrent cases to benefit from alkylating chemotherapeutics as, TMZ. Histopathologic parameters as DR, tumor budding, Inflammatory lymphocytic milieu (TIL-S, TIL-E, and CLR) and necrosis lack correlation with MGMT expression, however, were also associated with tumor progression, with a significant relationship between some parameters as DR with tumor budding and the mutual correlation between elements of the inflammatory (lymphocytic) milieu. Finally, these histopathologic parameters are advocated to be included into the routine diagnostic surgical pathology reports. 


\section{Acknowledgment}

The authors would like to thank Prof. Abdalla Khalil for valuable advices and support and Emad Hamdy (histotechnologist) for technical assistance in the study.

\section{References}

1. Sung H, Ferlay J, Siegel RL, Laversanne M, Soerjomataram I, Jemal A, et al. Global cancer statistics 2020: GLOBOCAN estimates of incidence and mortality worldwide for 36 cancers in 185 countries. CA Cancer J Clin. 2021:1:1-41. https://doi. org/10.3322/caac. 21660 PMid:33538338

2. Ioannou M, Paraskeva E, Baxevanidou K, Simos G, Papamichali R, Papacharalambous C, et al. HIF-1 $\alpha$ in colorectal carcinoma: Review of the literature. J BUON. 2015;20(3):680-9. PMid:26214618

3. Jeggo PA, Pearl LH, Carr AM. DNA repair, genome stability and cancer: A historical perspective. Nat Rev Cancer. 2016;16(1):3542. https://doi.org/10.1038/nrc.2015.4 PMid:26667849

4. Mojarad EN, Kuppen PJ, Aghdaei HA, Zali MR. The CpG island methylator phenotype (CIMP) in colorectal cancer. Gastroenterol Hepatol Bed Bench. 2013;6(3):120-8.

\section{PMid:24834258}

5. Sharma S, Salehi F, Scheithauer BW, Rotondo F, Syro LV Kovacs K. Role of MGMT in tumor development, progression, diagnosis, treatment and prognosis. Anticancer Res. 2009;29(10):3759-68.

PMid: 19846906

6. Cordeiro AT, Da Silva CM, Bartchewsky B Jr., Ribeiro ML, Martinez CA. Evaluation of the expression of the MGMT gene in normal and neoplastic tissue of patients with colorectal cancer. Rev Col Bras Cir. 2012;39(1):48-53. https://doi.org/10.1590/ s0100-69912012000100010 PMid:22481706

7. Lee KE. Immunohistochemical assessment of O(6)methylguanine-DNA methyltransferase (MGMT) and Its relationship with p53 expression in endometrial cancers. J Cancer Prev. 2013;18(4):351-4. https://doi.org/10.15430/ jcp.2013.18.4.351 PMid:25337565

8. Cankovic M, Nikiforova MN, Snuderl M, Adesina AM, Lindeman N, Wen PY, et al. The role of MGMT testing in clinical practice: A report of the association for molecular pathology. J Mol Diagn. 2013;15)5(:539-55. https://doi.org/10.1016/j. jmoldx.2013.05.011

PMid:23871769

9. Jacinto FV, Esteller M. MGMT hypermethylation: A prognostic foe, a predictive friend. DNA Repair (Amst). 2007;6(8):1155-60. https://doi.org/10.1016/j.dnarep.2007.03.013

PMid: 17482895

10. Zhang J, Stevens MF, Bradshaw TD. Temozolomide: Mechanisms of action, repair and resistance. Curr Mol Pharmacol. 2012;5(1):102-14

PMid:22122467

11. Reifenberger G, Hentschel B, Felsberg J, Schackert G,
Simon M, Schnell O, et al. Predictive impact of MGMT promoter methylation in glioblastoma of the elderly. Int $\mathrm{J}$ Cancer. 2012;131(6):1342-50. https://doi.org/10.1002/ijc.27385 PMid:22139906

12. Nagtegaal ID, Arends MJ, Telle S. Colorectal adenocarcinoma In: Nagtegaal ID, Arends MJ, Odze RD, Lam AK, editors. Tumors of the Colon and Rectum WHO Classification of Tumors Editorial Board. WHO Classification of Tumors: Digestive System Tumors. $5^{\text {th }}$ ed. Geneva: World Health Organization Press; 2019. p. 177-87. https://doi.org/10.1007/978-3-7091-6821-9_2

13. Jessup JM, Goldberg RM, Asare EA, Benson AB, Brierley JD, Chang GJ, et al. Colon and rectum. In: Amin MB, editor. AJCC Cancer Staging Manual. $8^{\text {th }}$ ed. New York: Springer Nature; 2017. p. 251-74.

14. Lugli A, Kirsch R, Ajioka Y, Bosman F, Cathomas G, Dawson H, et al. Recommendations for reporting tumor budding in colorectal cancer based on the international tumor budding consensus conference (ITBCC) 2016. Mod Pathol. 2017;30(9):1299-311. https://doi.org/10.1038/modpathol.2017.46 PMid:28548122

15. Ueno $H$, Kanemitsu $Y$, Sekine $S$, Ishiguro $M$, Ito $E$, Hashiguchi $\mathrm{Y}$, et al. Desmoplastic pattern at the tumor front defines poor-prognosis subtypes of colorectal cancer. Am J Surg Pathol. 2017;41(11):1506-12. https://doi.org/10.1097/ pas. 0000000000000946 PMid:28877064

16. Jakubowska K, Kisielewski W, Kanczuga-Koda L, Koda M, Famulski W. Stromal and intraepithelial tumorinfiltrating lymphocytes in colorectal carcinoma. Oncol Lett. 2017;14(6):6421-32. https://doi.org/10.3892/ol.2017.7013 PMid:29151905

17. Salgado R, Denkert C, Demaria S, Sirtaine N, Klauschen F, Pruneri $\mathrm{G}$, et al. The evaluation of tumor-infiltrating lymphocytes (TILs) in breast cancer: Recommendations by an International TILs working group 2014. Ann Oncol. 2015;26(2):259-71. https://doi.org/10.1093/annonc/mdu450

PMid:25214542

18. Väyrynen JP, Sajanti SA, Klintrup K, Mäkelä J, Herzig KH, Karttunen TJ, et al. Characteristics and significance of colorectal cancer associated lymphoid reaction. Int $\mathrm{J}$ Cancer. 2014;134(9):2126-35. https://doi.org/10.1002/ijc.28533 PMid:24154855

19. Richards $\mathrm{CH}$, Flegg KM, Roxburgh CS, Going JJ, Mohammed Z, Horgan PG, et al. The relationships between cellular components of the peritumoural inflammatory response, clinicopathological characteristics and survival in patients with primary operable colorectal cancer. Br J Cancer. 2012;106(12):2010-5. https:// doi.org/10.1038/bjc.2012.211

PMid:22596238

20. Sartore-Bianchi A, Pietrantonio F, Amatu A, Milione M, Cassingena A, Ghezzi S, et al. Digital PCR assessment of MGMT promoter methylation coupled with reduced protein expression optimises prediction of response to alkylating agents in metastatic colorectal cancer patients. Eur $\mathrm{J}$ Cancer. 2017;71:43-50. https://doi.org/10.1016/j.ejca.2016.10.032 PMid:27997874

21. Michailidi C, Theocharis S, Tsourouflis G, Pletsa V, Kouraklis G, Patsouris $\mathrm{E}$, et al. Expression and promoter methylation status of hMLH1, MGMT, APC, and CDH1 genes in patients with colon adenocarcinoma. Exp Biol Med (Maywood). 2015;240(12):1599605. https://doi.org/10.1177/1535370215583800 PMid:25908636

22. Pietrantonio F, De Braud F, Milione M, Maggi $C$, lacovelli $R$, Dotti KF, et al. Dose-dense temozolomide in patients with MGMTsilenced chemorefractory colorectal cancer. Target Oncol. 2016;11(3):337-43. https://doi.org/10.1007/s11523-015-0397-2 


\section{PMid:26538496}

23. Oliver JA, Oritz R, Melguizo C, Alvarez PJ, Millan JG, Prados J Prognostic impact of MGMT promoter methylation and MGMT and CD133 expression in colorectal adenocarcinoma. BMC Cancer. 2014;14:511. https://doi.org/10.1186/1471-2407-14-511 PMid:25015560

24. Zhang L, Zeng J, Zeng Z, Wang F, Wang D, Chen C, et al. MGMT in colorectal cancer: A promising component of personalized treatment. Tumor Biol. 2016;37(8):11443-56. https://doi. org/10.1007/s13277-016-5014-1 PMid:27006309

25. Liddell C, Droy-Dupré L, Métairie S, Airaud F, Volteau C, Bezieau S, et al. Mapping clinicopathological entities within colorectal mucinous adenocarcinomas: A hierarchical clustering approach. Mod Pathol. 2017;30(8):1177-89. https://doi. org/10.1038/modpathol.2017.18

PMid:28429715

26. Lugli A, Karamitopoulou E, Zlobec I. Tumour budding: A promising parameter in colorectal cancer. $\mathrm{Br} \mathrm{J}$ Cancer. 2012;106(11):1713-7. https://doi.org/10.1038/bjc.2012.127 PMid:22531633

27. Ueno $H$, Shinto $E$, Shimazaki $H$, Kajiwara $Y$, Sueyama $T$, Yamamoto $\mathrm{J}$, et al. Histologic categorization of desmoplastic reaction: Its relevance to the colorectal cancer microenvironment and prognosis. Ann Surg Oncol. 2015;22(5):1504-12. https:// doi.org/10.1245/s10434-014-4149-9 PMid:25395146

28. Cho SJ, Kakar S. Tumor budding in colorectal carcinoma: Translating a morphologic score into clinically meaningful results. Arch Pathol Lab Med. 2018;142(8):952-7. https://doi. org/10.5858/arpa.2018-0082-ra PMid:30040461

29. Klintrup K, Mäkinen JM, Kauppila S, Väre PO, Melkko J, Tuominen $\mathrm{H}$, et al. Inflammation and prognosis in colorectal cancer. Eur J Cancer. 2005;41(17):2645-54. https://doi. org/10.1016/j.ejca.2005.07.017

\section{PMid:16239109}

30. Rozek LS, Schmit SL, Greenson JK, Tomsho LP, Rennert HS Rennert G, et al. Tumor-infiltrating lymphocytes, Crohn's-like lymphoid reaction and survival from colorectal cancer. J Natl Cancer Inst. 2016;108(8):djw027. https://doi.org/10.1093/jnci/ djw027

\section{PMid:27172903}

31. Fuchs TL, Sioson L, Sheen A, Jafari-Nejad K, Renaud CJ, Andrici $\mathrm{J}$, et al. Assessment of tumor-infiltrating lymphocytes using international TILs working group (ITWG) system is a strong predictor of overall survival in colorectal carcinoma. Am J Surg Pathol. 2020;44(4):536-44. https://doi.org/10.1097/ pas. 0000000000001409

PMid:31743129

32. Pollheimer MJ, Kornprat P, Lindtner RA, Harbaum L, SchlemmerA Rehak $\mathrm{P}$, et al. Tumor necrosis is a new promising prognostic factor in colorectal cancer. Hum Pathol. 2010;41(12):1749-57. https://doi.org/10.1016/j.humpath.2010.04.018

\section{PMid:20869096}

33. Morano F, Corallo S, Niger M, Barault L, Milione M, Berenato R, et al. Temozolomide and irinotecan (TEMIRI regimen) as salvage treatment of irinotecan-sensitive advanced colorectal cancer patients bearing MGMT methylation. Ann Oncol. 2018;29(8):1800-6. https://doi.org/10.1093/annonc/mdy197 PMid:29860358

34. Mori Y. Nagasaka T, Tazawa H, Umeda Y, Morikawa T, Kubota N, et al. MGMT methylation as a novel biomarker for the identification of stage III colorectal cancers at high-risk of disease recurrence following curative surgery. Gastroenterology. 2013;144(5):S-85. https://doi.org/10.1016/s0016-5085(13)60315-7

35. Shah N, Lin B, Sibenaller Z, Ryken T, Lee H, Yoon JG, et al. Comprehensive analysis of MGMT promoter methylation: Correlation with MGMT expression and clinical response in GBM. PLoS One. 2011;6(1):e16146. https://doi.org/10.1371/ journal.pone.0016146

PMid:21249131 